\title{
Correspondance
}

\section{Climate change and health}

Tn the Feb. 15 issue of $C M A \mathcal{A}$, the 1 lead editorial ${ }^{1}$ and a commentary by Sari Kovats and Andrew Haines ${ }^{2}$ refer to "global average surface air temperature" and "global average surface temperature" respectively. It appears that this is a key indicator upon which inferences about "global warming" are based. Yet I have not been able to find an adequate description of the method by which this measure is obtained. Even as a nonclimatologist, I recognize that temperature varies by location, altitude, season, hour of the day and numerous other factors. The concept of an "average global temperature" is therefore very difficult to grasp.

Are there internationally agreedupon sampling sites, sampling times and sampling procedures for such calculations? Have these been in place for decades and applied consistently to allow us to comment on global historical trends, let alone make projections for the future? Do we know the $95 \%$ confidence intervals around these average temperatures? Until I have more information about how this critical indicator is measured, I cannot evaluate the "evidence" for an impact on health.

\section{Kue Young}

Department of Public Health Sciences

University of Toronto

Toronto, Ont.

\section{References}

1. The Kyoto Protocol: In force? [editorial]. CMAf 2005;172(4):437.

2. Kovats RS, Haines A. Global climate change and health: recent findings and future steps [editorial]. CMAf 2005;172(4):501-2.

DOI:10.1503/cmaj.1050123

$\mathrm{S}$ ari Kovats and Andrew Haines, in their commentary on the interrelationship between global climate change and health, ${ }^{1}$ comment on the increase in deaths from extreme heat in Europe, particularly France, during summer 2003. It is important to note that some of these deaths were due to the elevated tropospheric ozone levels that accom- panied the high temperatures. ${ }^{2}$ In the Netherlands, about 400 deaths were attributed to ozone, ${ }^{3}$ and similar calculations have been done for France and Britain.

In 1990, I reviewed the implications of global warming at a parliamentary conference, ${ }^{4}$ noting that increased ozone levels would occur unless precursor emissions were reduced. Neither Canada nor the United States has succeeded in effecting major reductions in the emissions of oxides of nitrogen, and these are still substantial, as illustrated in a recent newsletter from the North American Commission for Environmental Cooperation. ${ }^{5}$ It has also recently been documented that tropospheric ozone levels are slowly rising over the North Atlantic. ${ }^{6}$

Fortunately, any steps taken to reduce carbon dioxide emissions will also reduce oxide of nitrogen emissions, with a consequent lowering of ozone levels. All physicians should agree with Kovats and Haines that it is urgent for Canada not only to implement the Kyoto Protocol but also to take an international leadership role in urging much greater reductions.

\section{David V. Bates}

Professor Emeritus of Medicine University of British Columbia Victoria, BC

\section{References}

1. Kovats RS, Haines A. Global climate change and health: recent findings and future steps [editorial]. CMA7 2005;172(4):501-2.

2. Schwartz J. How sensitive is the association between ozone and daily deaths to control for temperature? Am 7 Respir Crit Care Med 2005; 171:627-31.

3. Fischer PH, Brunekreef B, Lebret E. Air pollution related deaths during the 2003 heat wave in the Netherlands. Atmos Environ 2004;38:1083-5.

4. Bates DV. Health effects of global warming. In: Parliamentary Forum on Global Climate Change; 1990 Apr 23-24. Ottawa: House of Commons.

5. First look at air pollution from over 1,000 fossilfuel power plants in North America. Trio [serial online] Winter 2003-2004;(14). Available: www.cec .org/trio/stories/index.cfm?ed=14\&ID=159\&varlan =english (accessed 2005 Apr 27).

6. Lelieveld J, Van Aardenne J, Fischer H, DeReus M, Williams J, Winkler P. Increasing ozone over the Atlantic Ocean. Science 2004;304:1843-7.

DOI:10.1503/cmaj.1050057 s Sari Kovats and Andrew Haines 1 have pointed out in a recent commentary, ${ }^{1}$ our world is warming up. Climate models predict that this increase in mean annual temperature will continue for the rest of the 21st century. Whatever the reasons for the temperature increase, climate change may have a greater impact on ecological processes than previously realized. ${ }^{2}$

There is mounting evidence that global climate change has extended growing seasons, changed distribution patterns and altered the phenology of flowering, breeding and migration. For migratory birds, the timing of arrival on breeding territories and overwintering grounds is a key determinant of reproductive success, survivorship and fitness. ${ }^{3}$

The Arctic Climate Impact Assessment (ACIA) report - the most comprehensive assessment of regional climate change ever undertaken - was released in November 2004. ${ }^{4}$ The report documents that the Arctic has experienced dramatic warming over the past 50 years, with winter temperatures increasing by as much as $3-4^{\circ} \mathrm{C}$. Over the past 30 years, the Arctic has lost almost a million square kilometres of sea ice, an area larger than Norway, Sweden and Denmark combined. ${ }^{4}$

Indigenous peoples and livelihoods are already severely affected by rising temperatures and sea levels, as are human settlements and economic infrastructure by thawing permafrost. These serious impacts will not occur decades in the future - they are being felt now. And they are being felt not just in remote islands halfway around the world, but also in some of the world's richest countries. Glacier retreat in Nepal, Peru and Switzerland, anomalous heat waves in France, and increasing sealevel and salt-water encroachment in Kiribati, Bangladesh and the United States are just a few examples of impacts related to climate change.

For several decades now we have been acutely aware of the increasingly intensifying effect that environmental degradation has on human health. Health experts are becoming more and 